\title{
POTENCY OF Curcuma aeruginosa AS A CHEMOPREVENTIVE CANDIDATE AGENT ON 7,12-Dimethylbenz[a]anthracene (DMBA)- INDUCED RAT SPLEEN
}

\author{
Asri Sulfianti ${ }^{1 *}$, Nur Hasanah ${ }^{2}$, Agung Eru Wibowo ${ }^{1}$, Kurnia Agustini ${ }^{1}$, \\ I Made Artika ${ }^{2}$ \\ ${ }^{1}$ Center of Pharmaceutical and Medical Technology, Agency for the Assessment and Application of \\ Technology, Indonesia \\ ${ }^{2}$ Department of Biochemistry, Bogor Agricultural University, Bogor, Indonesia
}

\begin{abstract}
Present investigation shows that the extract of $C$. aeruginosa attenuates DMBA-induced spleen carcinogenesis in Wistar rats. Three-week female Wistar rats were treated with three different $C$. aeruginosa extract doses (CA1: $40 \mathrm{mg} / 200 \mathrm{~g}$ body weight, BW; CA2: $80 \mathrm{mg} / 200 \mathrm{~g} \mathrm{BW}$; CA3: $160 \mathrm{mg} / 200 \mathrm{~g} \mathrm{BW}$ ) and were induced with DMBA after one-week administration of these doses. A commercial immunostimulant, and DMBA only were also given to each group as positive and negative control, respectively. The development of tumors was evaluated by investigating the incidence of tumor and tumor multiplicity during the experiment. Spleen mass index and histological parameters such as white pulp, centrum germinativum, and marginalis zone were also examined. Based on our study, the administration of $C$. aeruginosa extract during and after carcinogen induction gave several impacts on rat carcinogenesis. At the extract dose of $80 \mathrm{mg} / 200 \mathrm{~g} \mathrm{BW}$, tumor incidence of animals were least $(\mathrm{P}<0.05)$. However, all doses did not show any effect to the spleen mass index, though the highest dose $(160 \mathrm{mg} / 200 \mathrm{~g} \mathrm{BW})$ was found to cause changes in white pulp and marginalis zone boards. This trend indicates that it takes higher dose to cause an immune response effect reaching the organs.
\end{abstract}

Keywords: chemoprevention, cancer, Curcuma aeruginosa, DMBA, Wistar, spleen

${ }^{*}$ Corresponding author: Asri Sulfianti

Center of Pharmaceutical and Medical Technology

LAPTIAB BPPT Building NO 611-612, Puspiptek, Serpong, South of Tangerang, 15311, Indonesia.

Tel. +62-21-7560707, Fax. +62-21-7560707

E-mail. asri.sulfianti@bppt.go.id

\section{Introduction}

Cancer is a group of diseases characterized by uncontrolled growth and spread of abnormal cells (Garcia, Cristina, \& Jose, 2019; Haasanein et al., 2011). The resistance of cancer cells to chemotherapeutic agents becomes a major problem in the clinical treatment of cancer. In spite of astonishing advances in modern medicine, such as radiotherapy, surgery, and hormone therapy, cancer remains a worldwide health problem (Vijayarathna \& Sasidharan, 2012). One approach with enormous potential to overcome this problem is chemoprevention (Benetou, Lagiou, \& Lagiou, 2015; Desai et al., 2008). Chemoprevention is defined as the use of natural, synthetic or biological agents to reverse, suppress or prevent either the initial phases of carcinogenesis or the progression of premalignant cells to invasive disease (Benetou et al., 2015; Steward \& Brown, 2013; Tsao, Kim, \& Hong, 2004; Yang et al., 2011).

Plants are valuable natural product resources that offer compounds with a wide variety of biological activities and chemical structures (Benetou et al., 2015; Haasanein et al., 2011). However, the evaluation and the discovery of plant anticancer agents need a long-term process that encompasses many steps. The step broaches with the screening for anticancer properties, followed by the isolation and identification of bioactive compounds obliged to anticancer properties, toxicity estimation of the isolated compounds and eventually in vivo anticancer activity testing to 
verify the aptitude of the compounds (Vijayarathna \& Sasidharan, 2012).

One of Indonesian plant that has been used to treat cancer is Curcuma aeruginosa Roxb. This plant belongs to Zingiberaceae family. Plants in Zingiberaceae family are long known to have anti-inflammatory, antioxidant and many other biological properties that used for a variety of physiological disturbances, including cancer (Afzal, Oriqat, Akram Khan, Jose, \& Afzal, 2013). In Indonesia, $C$. aeruginosa is known by the local name as "Temuireng" because of its black rhizome (Simoh \& Zainal, 2015). Temuireng has been used as anticancer, disinfectant, expectorant, anthelmintic, antifungal, febrifuge, and antiinflammatory (Angel, Menon, Vimala, \& Nambisan, 2014; Atun, Arianingrum, Aznam, \& Ab Malek, 2016).

In present study, we investigated the chemoprevention effect of $C$. aeruginosa extraction on DMBA-induced rat's spleen. Chemically induced rodent models of cancer have been extensively used over the years to emulate human carcinogenesis. In these models, tumor can be induced in susceptible rat strains after single dose of carcinogens such as 7,12- dimethylbenz(a)anthracene (DMBA). Rat tumors are also not extremely invasive beyond the fat pad, have short latency, seldom metastasize and are highly hormonedependent. Moreover, most mouse strains are far more resistant than rats to chemicalinduced carcinogenesis, typically requiring multiple doses of carcinogens such as DMBA and developing only after a long latency (Abba et al., 2016).

Chemoprevention study on spleen was carried out because the spleen is the largest organ of the mononuclear phagocyte system and is involved in all systemic inflammation (Adelusola, Osasan, \& Afolabi, 2008; Jiang, Ma, \& Liu, 2018). The chemoprevention effect of $C$. aeruginosa on the spleen is an indicator how the active compound from the plant suppresse or prevents either the initial phases of carcinogenesis or the progression of cancer. This information is essential as a preliminary step to proceed with significant use of this herbal as a source of health-related products such as functional foods or pharmaceuticals to prevent cancer.

\section{Materials and Methods}

\section{Animals}

Female Wistar rats, 4 weeks- old, were purchased from Biofarma Inc. (Bandung, Indonesia) and housed in an environment control room maintained at $23 \pm 2^{\circ} \mathrm{C}, 60-70 \%$, relative humidity, $12: 12 \mathrm{~h}$ light/dark cycle, and standard food. All animal experiments were approved by Ethics Committee for Health Research, Medical School, University of Indonesia-Cipto Mangunkusumo Hospital, Jakarta, Indonesia.

\section{Plant Extraction}

C. aeruginosa rhizome was collected from a herb farm of Martha Thilaar. Dry rhizome was ground to a fine powder. The 5-kilogram simplicia powder was extracted with ethanol food grade, filtered and evaporated with a rotary evaporator (Axiovert). The extract was dissolved into CMC-Na $0.5 \%$ and divided into three-dose $(40 \mathrm{mg} / 200 \mathrm{~g} \mathrm{BW}, 80 \mathrm{mg} / 20 \mathrm{~g} \mathrm{BW}$ and $160 \mathrm{mg} / 200 \mathrm{~g} \mathrm{BW}$ ).

\section{Experimental Design}

Rats were divided into the following six groups ( $n=8$ per group): one used as untreated group or normal, one for immunostimulant as positive group control, one for DMBA treated only as negative control group, and three treatment groups which treated by three different $C$. aeruginosa extracts doses (CA1: $40 \mathrm{mg} / 200 \mathrm{~g} \mathrm{BW}$; CA2: $80 \mathrm{mg} / 200 \mathrm{~g} \mathrm{BW}$; CA3: $160 \mathrm{mg} / 200 \mathrm{~g} \mathrm{BW}$ ). For treatment groups, $C$. aeruginosa extract doses were given respectively in whole experiment for 20 weeks. After 2 weeks of extracts administration, rats were induced by DMBA for 2 weeks in whole treatment groups include negative and positive control groups.

In addition, it was not also given in the untreated or normal group. Three of each rat in every groups were sacrificed after 1 week DMBA (t1) induction to collect the spleen organs. Tumor incidence and tumor multiplicity have also been investigated. The development of the tumor was evaluated for 14 weeks until the end of the experiment. At the end of the experiment (t2), all rats were sacrificed and several organs were also collected to be observed. 
Tumor incidence and tumor multiplicity

Tumor incidence was calculated from the proportion of rats which had one or more tumors from the total number of rats. Chisquare or Fisher's exact tests were employed to test the differences in tumor incidence among groups. Tumor multiplicity was defined by the sum of tumor nodules found in each group. The distribution of tumor multiplicity was determined graphically and descriptively for skewness and normality. Analysis of variance was used to test for significant differences in tumor multiplicity. Moreover, post hoc pairwise comparisons were made using Tukey's honest significant differences.

\section{Tissue processing and histological analysis}

Spleens from all experimental rats were weighed immediately after removal to check out the spleen mass index and was fixed in buffered formalin for $48 \mathrm{~h}$. Spleen were removed, embedded in paraffin and stained with hematoxylin-eosin (HE staining) for histological analysis. The size and diameter of white pulp, centrum germinativum, and marginalis zone were measured to evaluate the impact of $C$. aeruginosa extracts on the spleen organ.

\section{Statistical analysis}

Statistical analyses were performed using Kruskall wallis or one-way analysis of variance (ANOVA), which each followed by Mann Whitney test and LSD post hoc test. The distribution of data was checked for normality by the Kolmogorov-Smirnov and Saphiro Wilk test. Numeric data for each A-series P value of $<0.05$ was regarded as significant. Statistical analysis was performed by the SPSS.016 software.

\section{Results}

\section{Rats body weights}

In the present study, the baseline measurements (before tumor induction) showed that the mean of body weights of rats was $50 \mathrm{~g}$. Moreover, after tumor induction by chemical carcinogen, the measured mean of body weights of rats was found to be increased progressively up to $200 \mathrm{~g}$ (Figure 1).

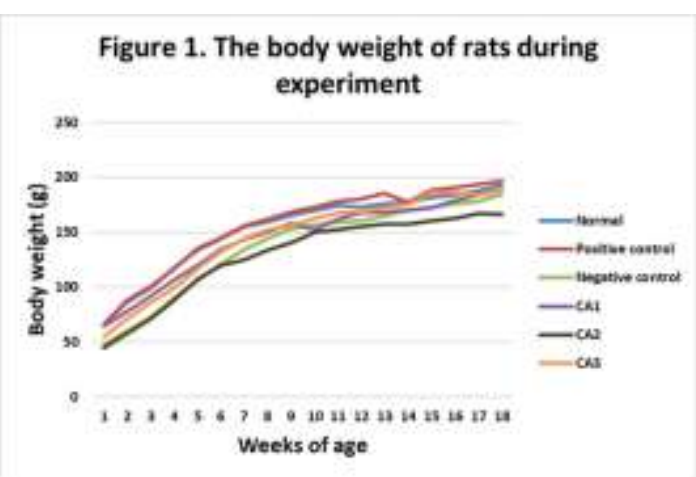

Figure 1. Bodyweight of rats during the experiment. N: Untreated/normal group; Negative control: DMBA only treated group positive control: treated by commercial immunostimulant; CA1: treated by $40 \mathrm{mg} / \mathrm{BW}$ doses of $C$. aeruginosa extract; CA2: treated by $80 \mathrm{mg} / \mathrm{BW}$ doses of $C$. aeruginosa extract; CA3: treated by $160 \mathrm{mg} / \mathrm{BW}$ doses of $C$. aeruginosa extract.

\section{Tumor incidence and tumor multiplicity}

Tumor incidence was calculated from the proportion of rats which had one or more tumors from the total number of rats, and tumor multiplicity was defined by the sum of tumor nodules found in each group. Based on the analysis, the negative control group with DMBA only gave the highest tumor incidence (100\%) and tumor multiplicity (1.25). In contrast, the CA2 was the least group with $50 \%$ of tumor incidence and tumor multiplicity (0.375) from all groups. It shows that in our study, no dose-dependent found that influences the tumor incidence and tumor multiplicity. Statistical significant differences were observed only in tumor incidence for the DMBA group compared to normal and CA2 group $(\mathrm{P} \leq 0,05)$, but not in tumor multiplicity (Figure 2).

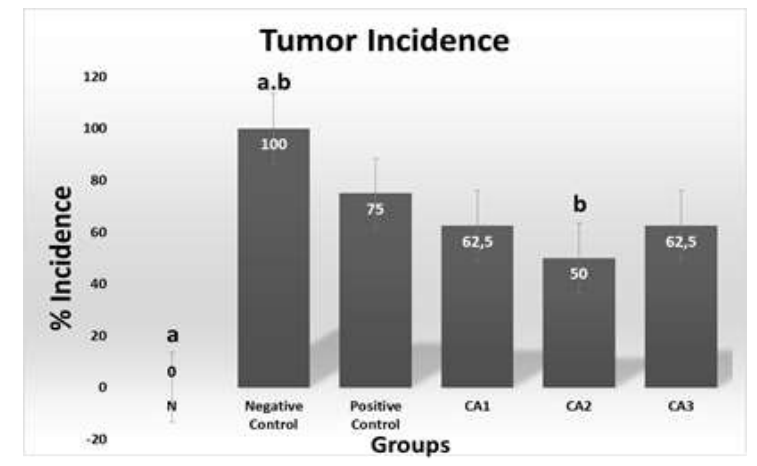




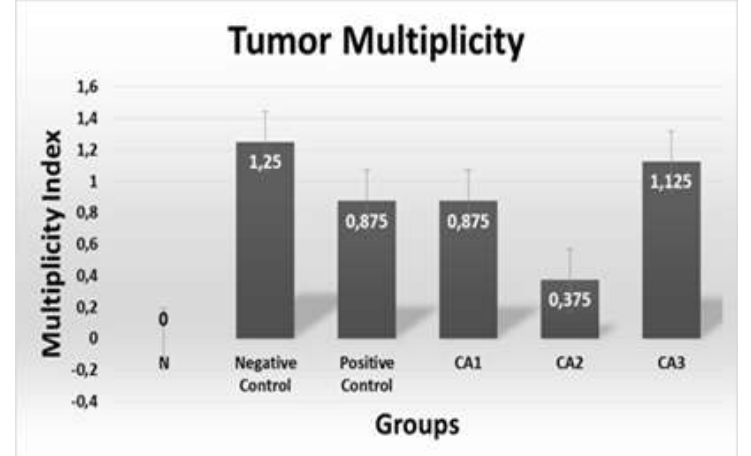

Figure 2. Tumor incidence and tumor multiplicity (a) Tumor incidence was expressed as the proportion of rats which had one or more tumors from the total number of rats \pm SE. (b) The average index of tumor multiplicity. Avarage tumor multiplicity for each treatment group was expressed as a number of tumors per-rats/total number of rats with tumors \pm SE. N: Untreated/normal group; negative control: DMBA only treated group; positive control: treated by commercial immunostimulant; CA1: treated by $40 \mathrm{mg} / \mathrm{BW}$ doses of $C$. aeruginosa extract; CA2: treated by $80 \mathrm{mg} / 200 \mathrm{~g} \mathrm{BW}$ doses of $C$. aeruginosa extract; CA3: treated by $160 \mathrm{mg} / \mathrm{BW}$ doses of C. aeruginosa extract.

\section{Spleen weights}

Mean and standard deviation of spleen weights for two different times were calculated and presented in Table 1 . In the baseline (1 week after DMBA induction = $\mathrm{t} 1$ ), spleen weights mean and SD values from all groups were $397,725 \pm 42,085 \mathrm{mg}$. Immediately after 14 week DMBA induction ( $\mathrm{t} 2)$, this means and SD values progressively increased to $528,703 \pm 85,406 \mathrm{mg}$. However, statistical difference showed that there was no significantly different between spleen weights at 1 week and that at 14-week after administration of DMBA $(\mathrm{P} \geq 0,05)$.

\section{Histological analysis}

The main histological changes such as wide of white pulp, marginalis zone, and centrum germinativum have been investigated at two different times, both at $\mathrm{t} 1$ and $\mathrm{t} 2$ time. Generally, all groups have a deterioration in wide of white pulp, except that of CA3 group which increase from 34061,638 $\pm 20125,993$ $\mu \mathrm{m}$ at 1 week to $82451,734 \pm 43354,407 \mu \mathrm{m}$ at 14 weeks after DMBA induction (Figure 3). Statistical differences observed in wide of white pulp showed that there were significantly differents in the groups of normal, DMBA, CA1, and CA3 at those two different time $(\mathrm{P} \leq 0,05)$. Moreover, the additional analysis found that CA3 statistically different from DMBA group at $\mathrm{t} 2$ (Table 2).

The similar pattern was also observed in the board of marginalis zone. All groups had a decline board of marginalis zone, except in CA3 group. Statistical analysis represented that normal, CA1, and CA3 groups had significantly differents in the board of marginalis zone at $\mathrm{t} 1$ and $\mathrm{t} 2$, whilst no difference was found in each group at $\mathrm{t} 2$ (Table $3)$. In addition, the decrease pattern also existed in centrum germinativum. In this parameter, the wide of centrum germinativum from all groups sized down, which DMBA and CA1 groups were found has significantly different at two different times. No significant differences were found in each group at $\mathrm{t} 2$ (Table 4).

Table 1. The averages of spleen index at two different times $(\mathrm{mg}) \pm$ S.D (Standard Deviation)

\begin{tabular}{lrlrrrr}
\hline Groups treatment & \multicolumn{3}{c}{ T1 } & \multicolumn{4}{c}{ T2 } \\
\hline Normal & 369,600 & \pm & 21,779 & 530,000 & \pm & 141,421 \\
DMBA (20 mg/200 g BW) & 276,900 & \pm & 25,739 & 528,888 & \pm & 163,335 \\
Imunostimulant (40 mg/200 g BW) & 393,350 & \pm & 2,051 & 505,000 & \pm & 25,884 \\
CA1 (dose 40 mg/200 g BW) & 413,000 & \pm & 141,421 & 491,667 & \pm & 28,577 \\
CA2 (dose 80 mg/200 g BW) & 359,500 & \pm & 12,021 & 526,667 & \pm & 38,079 \\
CA3 (dose 160 mg/200 g BW) & 532,000 & \pm & 49,497 & 590,000 & \pm & 115,140 \\
\hline
\end{tabular}

Table information: Different superscript letters in the same row showed there is significantly different $(\mathrm{P} \leq 0.05)$. 
Table 2. The averages of wide of white pulp at two different times $(\mu \mathrm{m}) \pm$ S.D (Standard Deviation)

\begin{tabular}{lll}
\hline Groups treatment & \multicolumn{1}{c}{ T1 } & \multicolumn{1}{c}{ T2 } \\
\hline Normal & $121175,011 \pm 44048,461^{\mathrm{a}}$ & $57042,542 \pm 32123,730^{\mathrm{a}}$ \\
DMBA $(20 \mathrm{mg} / 200 \mathrm{~g} \mathrm{BW})$ & $106434,052 \pm 53390,858^{\mathrm{b}}$ & $53754,220 \pm 34035,344^{\mathrm{b}, \mathrm{e}}$ \\
Imunostimulant $(40 \mathrm{mg} / 200 \mathrm{~g} \mathrm{BW})$ & $138677,346 \pm 80869,521$ & $62337,779 \pm 45325,083$ \\
CA1 (dose $40 \mathrm{mg} / 200 \mathrm{~g} \mathrm{BW})$ & $122228,809 \pm 43164,035^{\mathrm{c}}$ & $58478,003 \pm 32704,797^{\mathrm{c}}$ \\
CA2 (dose $80 \mathrm{mg} / 200 \mathrm{~g} \mathrm{BW})$ & $68400,525 \pm 28625,004$ & $56265,508 \pm 28042,773$ \\
CA3 (dose $160 \mathrm{mg} / 200 \mathrm{~g} \mathrm{BW})$ & $34061,638 \pm 20125,993^{\mathrm{d}}$ & $82451,734 \pm 43354,407^{\mathrm{d}, \mathrm{e}}$ \\
\hline
\end{tabular}

Table information: Different superscript letters in the same row showed there is significantly different $(\mathrm{P} \leq 0.05)$

Table 3. The averages of marginalis zones wide at two different times $(\mu \mathrm{m}) \pm$ S.D (Standard Deviation)

\begin{tabular}{llllllc}
\hline \multicolumn{1}{c}{ Groups Treatment } & \multicolumn{3}{c}{ T2 } & \multicolumn{3}{c}{ T3 } \\
\hline Normal & 9,793 & \pm & $1,321^{\mathrm{a}}$ & 6,791 & \pm & $1,609^{\mathrm{a}}$ \\
DMBA $(20 \mathrm{mg} / 200 \mathrm{~g} \mathrm{BW})$ & 8,023 & \pm & 3,862 & 5,779 & \pm & 2,342 \\
Imunostimulant (40 mg/200 g BW) & 8,047 & \pm & 1,772 & 6,979 & \pm & 2,636 \\
CA1 (dose $40 \mathrm{mg} / 200 \mathrm{~g} \mathrm{BW})$ & 9,579 & \pm & $4,660^{\mathrm{b}}$ & 6,842 & \pm & $4,227^{\mathrm{b}}$ \\
CA2 (dose $80 \mathrm{mg} / 200 \mathrm{~g} \mathrm{BW})$ & 6,987 & \pm & 1,826 & 5,994 & \pm & 1,607 \\
CA3 (dose $160 \mathrm{mg} / 200 \mathrm{~g} \mathrm{BW})$ & 3,945 & \pm & $0,589^{\mathrm{c}}$ & 6,433 & \pm & $1,783^{\mathrm{c}}$ \\
\hline
\end{tabular}

Table information: Different superscript letters in the same row showed significant differences $(\mathrm{P} \leq 0.05)$.

Table 4. The averages of wide of centrum germinativum at two different times $(\mu \mathrm{m}) \pm$ S.D (Standard Deviation)

\begin{tabular}{lrrrrrr}
\hline Groups treatment & \multicolumn{3}{c}{ t1 } & \multicolumn{3}{c}{ t3 } \\
\hline Normal & 1130,525 & \pm & 670,29 & 493,775 & \pm & 327,458 \\
DMBA (20 mg/200 g BW) & 106434,052 & \pm & $53390,858^{\mathrm{a}}$ & 572,622 & \pm & $346,353^{\mathrm{a}}$ \\
Imunostimulant (40 mg/200 g BW) & 138677,346 & \pm & $80869,521^{\mathrm{b}}$ & 534,265 & \pm & $467,791^{\mathrm{b}}$ \\
CA1 (dose 40 mg/200 g BW) & 122228,809 & \pm & 43164,04 & 727,271 & \pm & 668,142 \\
CA2 (dose 80 mg/200 g BW) & 68400,525 & \pm & 28625 & 743,974 & \pm & 656,555 \\
CA3 (dose 160 mg/200 g BW) & 34061,638 & \pm & 20125,99 & 717,653 & \pm & 574,409 \\
\hline
\end{tabular}

Table information: Different superscript letters in the same row showed there is significantly different $(\mathrm{P} \leq 0.05)$.

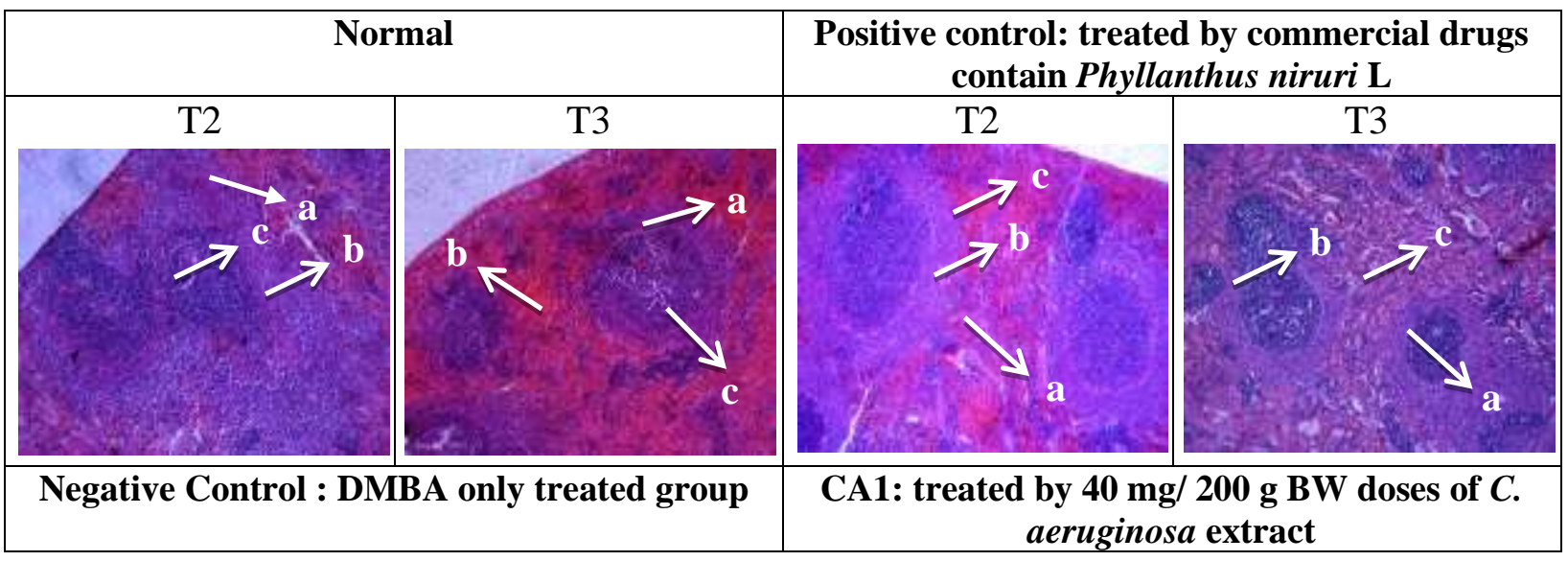




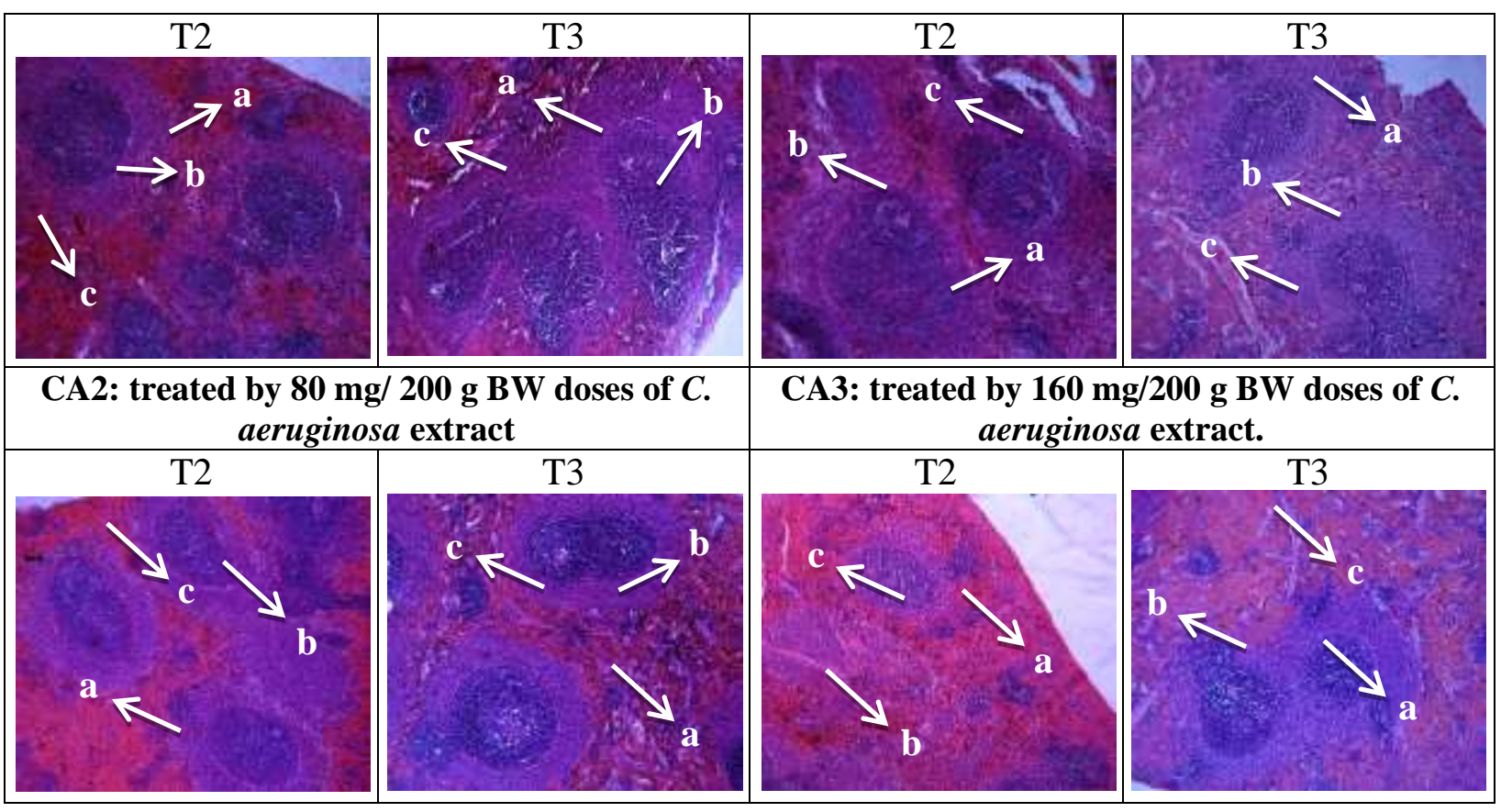

Figure 3. Histological changes on spleen after haematoxylin-eosin staining at two different times, $t 2$ and t3. Information: (a) marginalis zone (b) white Pulp, (c) centrum. N: Untreated/normal group; negative control: DMBA only treated group; positive control: treated by commercial immunostimulant; CA1: treated by $40 \mathrm{~g} / 200 \mathrm{~g}$ BW doses of $C$. aeruginosa extract; CA2: treated by 80 g/ $200 \mathrm{~g} \mathrm{BW}$ doses of $C$. aeruginosa extract; CA3: treated by $160 \mathrm{~g} / 200 \mathrm{~g} \mathrm{BW}$ doses of $C$. aeruginosa extract.

\section{Discussion}

Cancer is a group of diseases that can occur in all living cells in the body. Epidemiological studies have shown that 70-90\% of all cancers associate with environmental factors. Those factor, may act as initiators, promoters, or both roles that cause carcinogenesis. DMBA is one of chemical carcinogens which commonly employed to initiate and promote neoplastic transformation/carcinogenesis in experimental animal. Hence, the present study was undertaken to investigate the toxicity induced by DMBA and anticancer potential of $C$. aeruginosa. The cancer chemopreventive efficacy was assessed by its ability to modulate the rat body weight gain during carcinogenesis, the incidence of tumor, tumor multiplicity, and its influence on spleen as immune organ.

Based on our experiment, the administration of $C$. aeruginosa extracts before and after DMBA initiation has successfully controlled the rat body weight gain during carcinogenesis. Figure 1 shows the escalation of body weight gain in rats during the experiment. The escalating pattern of body weight gain was seen in all groups. However, the positive and normal control still had higher body weight than those of the treated groups by $C$. aeruginosa extracts. Theoretically, depression of body weight gain is frequently employed as a non-specific indicator of toxicity in chemoprevention studies in rats. In the evaluation of potential chemopreventive agents in rodent mammary cancer models, it has generally been accepted that a final body weight gain depression of $15 \%$ or less is tolerable in animals receiving the agent (Rogers, Sullivan, \& Hafer, 1999). However, in this study, the body weights gain in rats were increased, even after the administration of DMBA for 2 weeks.

The weight gain in rats also influences their survival rate. As shown in the result, groups treated with $C$. aeruginosa extracts had lower tumor incidence and tumor multiplicity than those of the DMBA group. In addition, CA2 was the group with the smallest tumor incidence and tumor multiplicity, compared to other CA dose groups. It was shown that 80 $\mathrm{mg} / 200 \mathrm{~g} \mathrm{BW}$ of $C$. aeruginosa extract was the best dose to decrease the tumor incidence in our model experiment. It is generally assumed 
that there exists a well-defined relationship between drug dose and drug effect which commonly expressed by a dose-response curve. However, tolerance development during the administration of CA2 dose may cause major distortion of the curve. Studies found that, there are several factors which influence the effect of a drug on an individual depending on the dynamic relation between several variables, particularly the level of tolerance, the dose anticipated by the organism and the actual drug dose.

The devaluation of cancer in rat group treated by CA extracts was due to the fact that this herb contains many phytochemicals which have been discovered to be anticancer agents. Several researchers found that curzerene, cineole, germacrone, and $\beta$-element in $C$. aeruginosa posses anticancer activities. Other study also reported that sesquiterpenoid germacrone exhibited the best anticancer properties by inhibiting cell proliferation, increasing lactate dehydrogenase, and mediating G1 and G2 cell cycle arrest in human breast cancer. (Abba et al., 2016; Simoh \& Zainal, 2015).

Macroscopic examination showed the induction of DMBA and administration of $C$. aeruginosa extracts in all treatment groups led to the decreased spleen mass index. The location of the spleen in the abdomen, where it is not protected by a bony cage, also makes it is very prone to traumatic injury (Adelusola $e t$ al., 2008; Jiang et al., 2018). Moreover, this carcinogen also caused the changing of spleen color. Normally, rat spleen has a dark red to blue-black, with an elongated shape and roughly triangular in cross-section. In contrast, in the DMBA treated group, the color of the spleen was darker, with blunt shape and it broke easily (Cesta, 2006; Jiang et al., 2018).

The alteration was also found in spleen histopathological observation. Microscopic qualitative observations of the spleen revealed peripherally positioned red pulp and centrally located white pulp (Petrovova, Massanyi, Capcarova, Zivcak, \& Stodola, 2011). The red pulp is composed of a three-dimensional meshwork of splenic cords and venous sinuses. It has been known that the splenic cords are composed of reticular fibers, reticular cells, and are associated with macrophages. Moreover, the white pulp, located around a central arteriole, is composed of the periarteriolar lymphoid sheath (PALS, T-cell area), the adjacent follicles (B-cell area), and marginal zone (B-cell area) (Cesta, 2006; Elmore, 2012).

In this study, we found a decrement in all wide and board of histological parameters such as white pulp, centrum germinativum, and marginalis zone. Induction by DMBA and chemopreventive did not cause the accession of these areas, which indicated the immune activities. Only CA3 dose was able to increase the wide of white pulp and board of marginal zone after DMBA induction. Generally, lymphocytes freely pass through the spleen, but in this case, DMBA leads to hold lymphocytes and they are not able to leave the spleen. As consequence, there was an exaggeration in spleen white pulp which indicates the activity of $\mathrm{T}$ and $\mathrm{B}$ cells to kill the cancer cells. Moreover, lymphocytes, dendritic cells, and specific macrophages in the marginal zone also been promoted to grow and invade the cancer cells during carcinogenesis (Kumararatne, MacLennan, Bazin, \& Gray, 1982). Macrophages in the immune response are considered to be a phagocyte system, which may occasionally be dependent on the state of the host immune reaction as well as maintenance of the antigen, such as DMBA (Abdalla, Rocha Aleixo, Murta, \& Michelin, 2014).

In summary, the administration of $C$. aeruginosa extract as chemopreventive agent during and after carcinogen induction gave several impacts in rat carcinogenesis. The results presented in this study demonstrate that $C$. aeruginosa may be used as a cancer chemopreventive candidate agent by virtue of its effect on tumor incidence and spleen microscopic. This ability may due to the presence of phytochemicals in this plant. Hence, , further studies to discover active compound which responsible as anticancer is needed to disclose the mechanism in cells.

\section{Acknowledgements}

We are grateful to the Center of Pharmaceutical and Medical Technology, Agency for the Assessment and Application of Technology for financial support . 


\section{References}

Abba, M. C., Zhong, Y., Lee, J., Kil, H., Lu, Y., Takata, Y., Simper, M.S., Gaddis, S., Shen, J., Marcelo Aldaz, C. (2016). DMBA induced mouse mammary tumors display high incidence of activating Pik3caH1047and loss of function Pten mutations. Oncotarget, 7(39): 6428964299. https://doi.org/10.18632/oncotarget.117 33

Abdalla, D. R., Rocha Aleixo, A. A., Murta, E. F. C., \& Michelin, M. A. (2014). Innate immune response adaptation in mice subjected to administration of DMBA and physical activity. Oncology Letters, 7(3): 886-890. https://doi. org/10.3892/ol.2013.1774.

Adelusola, K., Osasan, S., \& Afolabi, O. (2008). Histopathological study and audit of the spleen in Nigerians. African Journal of Health Sciences, 14(3): 195-200. https://doi.org/10. 4314/ajhs.v14i3.30865

Afzal, A., Oriqat, G., Akram Khan, M., Jose, J., \& Afzal, M. (2013). Chemistry and biochemistry of terpenoids from Curcuma and related species. Journal of Biologically Active Products from Nature, 3(1): 1-55. https://doi.org/10.1080/ 22311866.2013.782757

Angel, G. R., Menon, N., Vimala, B., \& Nambisan, B. (2014). Essential oil composition of eight starchy Curcuma species. Industrial Crops and Products, 60: 233-238. https://doi.org/10.1016/ j.indcrop.2014.06.028

Atun, S., Arianingrum, R., Aznam, N., \& Ab Malek, S. N. (2016). Isolation of sesquiterpenes lactone from Curcuma aeruginosa rhizome and the cytotoxic activity against human cancer cell lines. International Journal of Pharmacognosy and Phytochemical Research, 8(7): 1168-1172.

Benetou, V., Lagiou, A., \& Lagiou, P. (2015). Chemoprevention of cancer: Current evidence and future prospects. F1000Research, 4: 1-10. https://doi.org/10.12688/f1000research.6684.1

Cesta, M. (2006). Normal Structure, Function, and Histology of the Spleen . Toxicologic Pathology, 34(7): 455-465. https://doi.org/10. 1080/01926230600867743

Desai, A. G., Qazi, G. N., Ganju, R. K., El-Tamer, M., Singh, J., Saxena, A. K., Bedi, Y. S., Taneja, S. C., Bhat, H. K. (2008). Medicinal plants and cancer chemoprevention. Current Drug Metabolism, 9(7): 581-591. https://doi. org/10.1037/a0013262

Elmore, S. A. (2012). Enhanced Histopathology of the Immune System: A Review and Update . Toxicol Pathol, 40(2): 148-156. https://doi.org/ $10.1177 / 0192623311427571$

Garcia, C., Cristina, S., \& Jose, J. (2019). Dietary flavonoids as cancer chemopreventive agents :
An updated review of human studies.

Antioxidants, 8(137): 1-23.

Haasanein, H., El-ahwany, E., Salah, F., Hammam, O., Refai, L., \& Hamed, M. (2011). Extracts of five medicinal herbs induced cytotoxicity in both hepatoma and myeloma cell lines. Journal of Cancer Science \& Therapy, 3(10): 239-243. https://doi.org/10.4172/1948-5956.1000097

Jiang, Z., Ma, F., \& Liu, X. (2018). Squamous cell carcinoma of the spleen: A case report. Oncology Letters, 16: 3973-3975. https://doi. org/10.3892/ol.2018.9095

Kumararatne, D. S., MacLennan, I. C., Bazin, H., \& Gray, D. (1982). Marginal zones: The largest B cell compartment of the rat spleen. Advances in Experimental Medical and Biology, 149: 67-73.

Petrovova, E., Massanyi, P., Capcarova, M., Zivcak, J., \& Stodola, L. (2011). Structural alterations in rabbit spleen after bendiocarb administration. Journal of Environmental Science and Health Part B-Pesticides Food Contaminants and Agricultural Wastes, 46(8): 788-792.https://doi.org/10.1080/03601234.20 12. 601937

Rogers, A. E., Sullivan, L. M., \& Hafer, L. J. (1999). Dietary fat, body weight, and cancer: Contributions of studies in rodents to understanding these cancer risk factors in humans. Toxicological Sciences, 52: 66-71.

Simoh, S., \& Zainal, A. (2015). Chemical profiling of Curcuma aeruginosa Roxb. rhizome using different techniques of solvent extraction. Asian Pacific Journal of Tropical Biomedicine, 5(5): 412-417. https://doi.org/10.1016/S2221-1691 (15)30378-6.

Steward, W. P., \& Brown, K. (2013). Cancer chemoprevention: A rapidly evolving field. British Journal of Cancer, 109 (1): 1-7. https://doi.org/10.1038/bjc.2013.280

Tsao, A. S., Kim, E. S., \& Hong, W. K. (2004). Chemoprevention of cancer. CA: A Cancer Journal for Clinicians, 54 (3): 150-180. https://doi.org/10.3322/canjclin.54.3.150

Vijayarathna, S., \& Sasidharan, S. (2012). Cytotoxicity of methanol extracts of Elaeis guineensis on MCF-7 and Vero cell lines. Asian Pacific Journal of Tropical Biomedicine, 2(10), 826-829. https://doi.org/10.1016/S2221-1691 (12)60237-8

Yang, C. C., Hsieh, Y. C., Lee, S. J., Wu, S. H., Liao, C. L., Tsao, C. H., Chern, J. H., Wu, C. P., Yueh, A. (2011). Novel dengue virus-specific NS2B/NS3 protease inhibitor, BP2109, discovered by a high-throughput screening assay. Antimicrobial Agents and Chemotherapy, 55(1): 229-238. https://doi.org/10.1128/AAC. 00855-10 